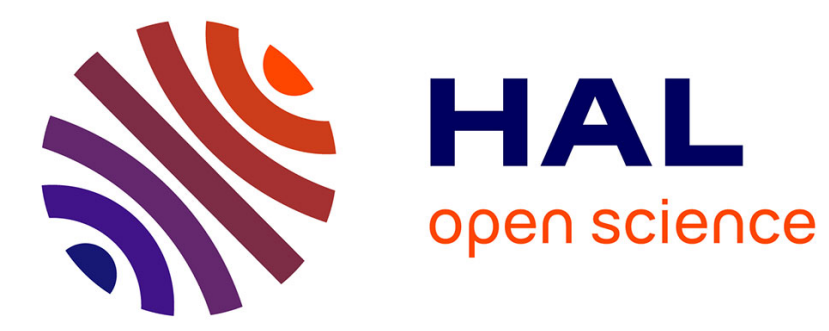

\title{
THERMO-MECHANICAL INSTABILITY OF LAYERS IN A SMECTIC-A LIQUID CRYSTAL
}

R. Ribotta

\section{To cite this version:}

R. Ribotta. THERMO-MECHANICAL INSTABILITY OF LAYERS IN A SMECTICA LIQUID CRYSTAL. Journal de Physique Colloques, 1976, 37 (C3), pp.C3-149-C3-153. 10.1051/jphyscol:1976329 . jpa-00216512

\section{HAL Id: jpa-00216512 https://hal.science/jpa-00216512}

Submitted on 1 Jan 1976

HAL is a multi-disciplinary open access archive for the deposit and dissemination of scientific research documents, whether they are published or not. The documents may come from teaching and research institutions in France or abroad, or from public or private research centers.
L'archive ouverte pluridisciplinaire HAL, est destinée au dépôt et à la diffusion de documents scientifiques de niveau recherche, publiés ou non, émanant des établissements d'enseignement et de recherche français ou étrangers, des laboratoires publics ou privés. 


\title{
THERMO-MECHANICAL INSTABILITY OF LAYERS IN A SMECTIC-A LIQUID CRYSTAL
}

\author{
R. RIBOTTA \\ Laboratoire de Physique des Solides (*), Université de Paris-Sud, 91405 Orsay, France
}

\begin{abstract}
Résumé. - On décrit une expérience permettant de provoquer une instabilité d'ondulation des couches smectiques par l'application locale d'un brusque échelon de température. On explique cet effet par une brusque diminution de l'épaisseur des couches. La mesure de la puissance-seuil dissipée en fonction de la température de l'échantillon montre une inversion inattendue du sens de variation de l'épaisseur des couches dans certains composés. Cette expérience peut constituer une méthode très sensible de mesure de l'expansion thermique des couches.
\end{abstract}

\begin{abstract}
We describe here an experiment in which the undulation instability of layers in a smectic phase can be obtained by locally submitting a sample to temperature steps. This effect is interpreted as due to the rapid contraction of the layers. Some compounds show when the sample temperature is varied an unexpected inversion of the sign of thickness variation of the layers. From this experiment one can deduce a highly sensitive way of measuring thermal variations of the layer thickness.
\end{abstract}

Smectic-A liquid crystal samples show when submitted to uniaxial dilative stresses normal to the layers, an instability of structure, which appears as an undulation of these layers $[1,2]$.

This instability is obtained for a displacement $\delta$ of the upper plate, exceeding a certain threshold $\delta_{\text {th }}=2 \pi \lambda$ where $\lambda$ is the de Genne's penetration depth defined [3] as $\lambda=\left(K_{1} / \bar{B}\right)^{1 / 2}, K_{1}$ is the Frank elastic constant associated with the splay of molecules and $\bar{B}$ is the elastic modulus normal to the layers. The length $\lambda$ is on the order of a molecular length and has already been measured by various methods $[1,4,5,6]$. The undulation appears in a sample of thickness $d$ with a wavevector $q_{\mathrm{c}}=(\pi / \lambda d)^{1 / 2}$, and has a finite duration time limited by the relaxation of the tension due to the motion of edge dislocations.

It had already been reported in reference [1] that this instability could appear by sudden interruption of a powerful $\mathrm{He}-\mathrm{Ne}$ laser beam illuminating the sample, indicating that rapid thermal changes can have a destabilizing action on the layered structure. This is confirmed by observation of the undulated structure which appears when the transition from the nematic to the smectic phase is made rapidly in a usual sample. More often is observed the double-crossed grating which evolves to the regular array of focal conics domains [4]. It has been shown by X-Ray scattering experiments that long aliphatic chains become more flexible and then shorten their average total length when the temperature increases [7]. Then in a given homeotropic sample of fixed thickness, an increase of temperature would produce a uniaxial negative stress

(*) Laboratoire associé au C. N. R. S. (dilation) by decreasing the layer thickness. This would be equivalent to applying a dilative stress normal to the layers on a sample at a fixed temperature. However, as in mechanical instabilities this stress will stimulate the motion ( $\operatorname{climb}$ ) of edge dislocations. These dislocations move in order to fill the extra-space created by the contraction of layers, and therefore relax the stress.

The instability being then temporary it is necessary, in order to obtain it, to apply a temperature change in a time smaller than the relaxation time. Under this condition we may define a threshold in applied power above which the undulation will appear. The thermal quantities of smectics are poorly known and it is experimentally more convenient here to use the applied power $\Delta P$ as the parameter, rather than the created excess of temperature $\Delta T$. Then we may define a total thermal expansion coefficient $\alpha$ by :

$$
\delta=-\alpha d \Delta P
$$

where $\delta$ is the total expansion normal to the layers of a sample of thickness $d$. An instability can be obtained when

$$
\delta=\delta_{\mathrm{th}}=-\alpha d \Delta P_{\mathrm{th}}=2 \pi \lambda .
$$

Experimentally the sudden temperature changes are produced by an electric current passing through a resisting constantan wire $(50 \mu \mathrm{m}$ diameter $)$ which traverses the $330 \mu \mathrm{m}$ thick sample. This sample is prepared between $\lambda / 8$, polished silica-fused plates which are coated with HTAB (hexadecyltrimethylammoniumbromide) in order to favour the homeotropic alignment.

The steps of current are applied with a risetime of order $10 \mathrm{~ms}$. The sample is placed in a oven having a 
temperature definition not better than $0.2^{\circ} \mathrm{C}$ and is observed under a polarizing microscope. We check that there is no visible defect of structure produced by the wire, and that this wire does not move when current steps are applied. We find indeed that above a certain value of the electrical current, undulations of layers appear close to the wire and using the same experimental procedure three different compounds are studied :

- HOBHA (or 70.7) : heptyl-oxy-benzilidene-p-nheptyl-aniline, which presents a smectic- $A$ phase between $72^{\circ} \mathrm{C}$ and $83.7^{\circ} \mathrm{C}$ and a first order transition upwards to the nematic phase, and a second order transition downwards to the smectic- $\mathrm{C}$ phase.

- CBOOA : cyano-benzilidene-p-n-octyl-oxy-aniline, which has a smectic-A phase between $73.2^{\circ} \mathrm{C}$ and $83^{\circ} \mathrm{C}$ and presents a quasi-second order transition to the nematic phase. It has a bi-layered structure.

- BBAA : butoxy-benzilidene-p-n-anilino-acetophenone, which has a smectic-A phase between $84^{\circ} \mathrm{C}$ and $93{ }^{\circ} \mathrm{C}$ and presents a first order transition to the nematic phase.

1. Power threshold measurements in the HOBHA. At various fixed temperatures of the sample we measure the minimum current step necessary to produce an instability. This minimum corresponds to the appearance of undulations right close to the wire on both sides. These undulations are parallel to the wire and extend on a width comparable to the wire diameter $(50 \mu \mathrm{m})$ (see Fig. 1). The spacing is of order $3-4 \mu \mathrm{m}$.

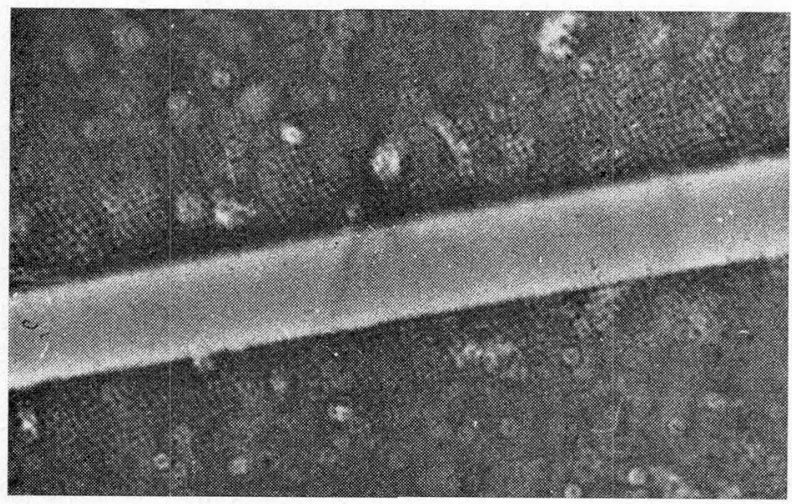

Fig. 1. - Observation under a polarizing microscope of the undulations of layers that appear close to the wire. In order to obtain a good photographic contrast the thermal power has been made large and we obtain here the double crossed grating instead of the simple grating.

These deformation last for a short time (about $0.1 \mathrm{~s}$ ) and disappear at about the same time on their whole extension. Careful observation using the dark background technique can show that amidst the undulated zone very thin light lines equally spaced (about 10$15 \mu \mathrm{m}$ long) move rapidly $(50-100 \mu \mathrm{m} / \mathrm{s})$ from far in the direction of the wire and normal to it, i. e. normal to the undulations lines. The lines have already been observed in the buckling instability experiment [6] and they had been identified as small Burgers vector edgedislocations. The measured velocity close to threshold was of the same order $(50-100 \mu \mathrm{m} / \mathrm{s})$. If the current amplitude is increased well above the threshold, the undulated zone width increases, the thin light lines are still moving towards the wire and stop there. Then starting from the wire and moving in the apposite direction a large wave-front can be seen which wipes out the undulated structure (Fig. 2). Its velocity is

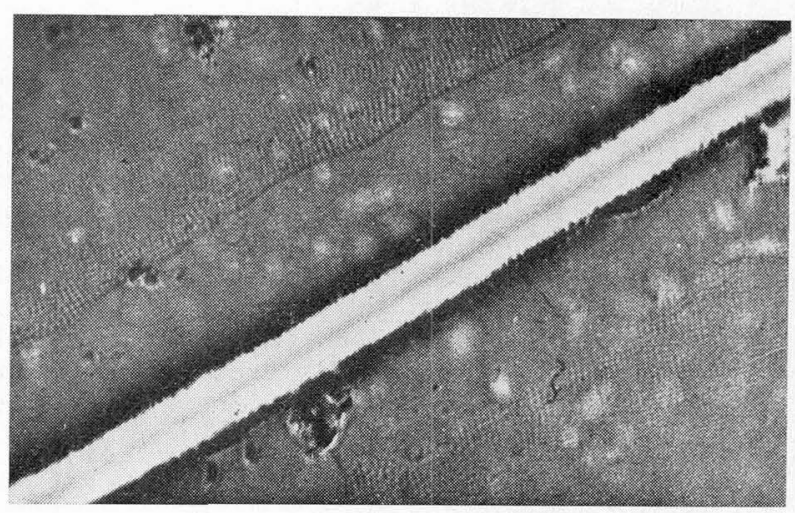

FIG, 2, - Disappearance of the Lis.dulated structure due to the wave which moves from the wire and normal to it. In the region close to the wire the structure is now at rest and urperturbed.

slower, ranging from 10 to $20 \mu \mathrm{m}$ per second. This wave is thought to be an edge-dislocation of large Burgers vector that would correspond to $2 \pi \lambda / a$ layers ( $« a »$ being the layer thickness).

Now, varying the sample temperature from the nematic to the smectic-C phase we find that undula-

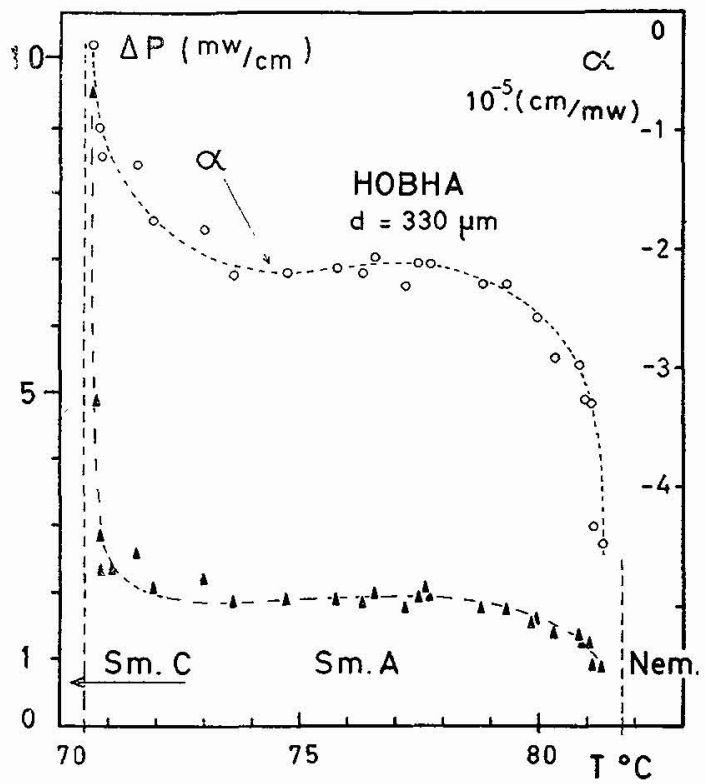

FIG. 3. - Temperature dependence of the electrical power threshold in a sample of HOBHA. The expansion coefficient $\alpha$ is calculated taking into account the temperature dependence of the mechanical threshold $\delta_{\text {th }}$ found experimentally for this compound [6]. 
tions are still produced for a positive step of current (heating phase). The temperature dependence of the threshold shows a small decrease to the nematic transition and a very sharp increase close to the smectic-C transition (Fig. 3).

2. In the CBOOA. - Using the same method, we observe here similar effects. However we find two distinct regions (Fig. 4), one in which the instability is

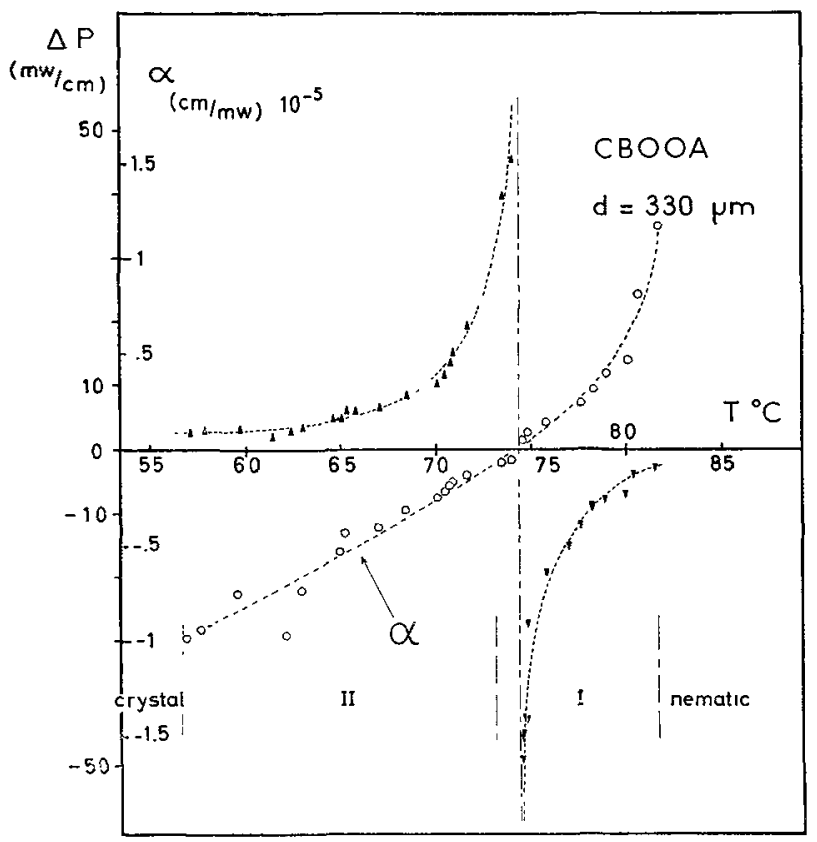

Fig. 4. - Temperature dependence of the electrical power threshold in CBOOA showing the inversion effect. The normal smectic range is region I while the supercooled smectic range is region II. The variation of the expansion coefficient shows the change of sign. The temperatures indicated here have been corrected for heating by the wire.

obtained only for positive steps (heating phase $\Delta P>0$ ), the other one in which it is obtained only for negative steps : $\Delta P<0$ (the current has been established for a while then suddenly cut out). The new effect indicates that the expansion coefficient of the layers changes its sign. In the lower temperatures region we would have the classical rubber-type contraction as for the previous compound and in the higher temperatures region the solid-type dilation effect. Note that this compound shows a large crystallization delay, We have observed in this second region, during the establishment of the current that on both sides of the wire two ribbon-like zones move away from the wire and normal to it. These zones appear weakly illuminated on the dark background (between crossed polarizers), possibly due to a partial tilting of the molecular axis. In effect, applying a temperature step which dilates the layers in a sample of fixed total thickness would be equivalent to applying a compressive stress normal the layers [8].
3. In the BBAA. - We find for this compound two different behaviours as for the CBOOA. However, in the lower temperatures region, which is relatively narrow, the threshold increases sharply close to the crystalline phase (Fig. 5), indicating a strong decrease of the expansion coefficient close to this phase.

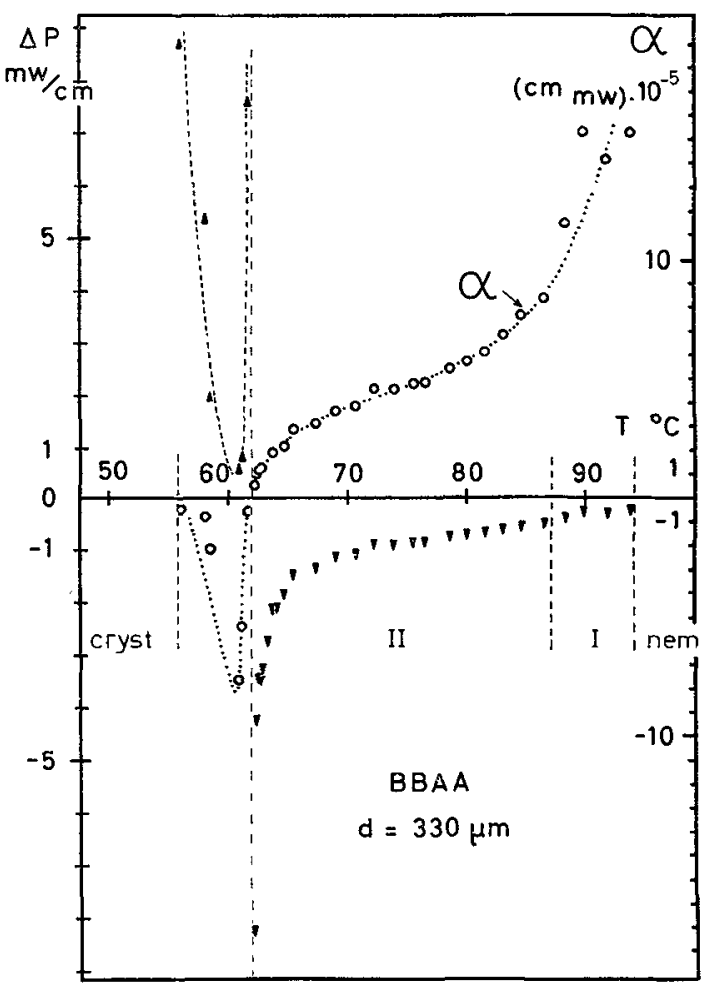

FIG. 5. - The temperature dependence of the threshold shows in BBAA an inversion as for the CBOOA. Here too, the supercooled region is II, while the normal smectic range is $I$. The temperatures are not here corrected for heating by the wire. Here $\alpha$ is calculated assuming the mechanical threshold $\delta_{t \mathrm{~h}}$ is constant over the smectic range.

4. Interpretation of the results. - We have shown that thermal steps can produce undulation instabilities of layers. The lowest threshold power is of order $1 \mathrm{~mW} / \mathrm{cm}$ of wire. In a $330 \mu \mathrm{m}$ thick sample the threshold correspond to a decrease of about $10^{-3} \AA$, in the molecular length.

In order to give a precise account of the effect, one should measure the temperature of the volume submitted to the thermal steps. However, such measurements were not possible in our set-up and the values reported for the temperature are average values measured against the upper glass plate of the sample. This procedure seems valid only for the lower values of the power threshold. A Copper-Constantan thermocouple, diameter $70 \mu \mathrm{m}$, was introduced into the sample at a distance of $200 \mu \mathrm{m}$ from the wire (i. e. outside the undulated zone). The increase in temperature due to a step in power of $1 \mathrm{~mW} / \mathrm{cm}$ was approximately $1.5 \times 10^{-2}{ }^{\circ} \mathrm{C}$. This rough measurement obviously can give only a lower limit for the exact value 
close to the wire. Thus, when interpreting the data, one must take into account the increase of temperature due to heating by the wire. This is espacially true close to the inversion point, where the power thresholds $\Delta P$ are large, and negative. In this region of negative $\Delta P$ the actual experimental procedure consisted of heating the sample for several seconds with a $\Delta P$ close to threshold and then suddenly suppressing the heat flux. The excess of temperature can be large and the effect of corrections on the data are to displace the inversion point towards higher temperatures. Since this correction is difficult to make, we assume that the variation of the expansion coefficient must be quasi-monotonic around the inversion point and displace this point in order to realize that condition.

On the measured temperature scale therefore the data show in the neighbourhood of the inversion point, a sharp break in the expansion coefficient curve which has no physical meaning. We find then that the displacement is approximately $4^{\circ} \mathrm{C}$, indicating an increase $\Delta T=8 \times 10^{-2}{ }^{\circ} \mathrm{C} / \mathrm{mW}$, six times as large as the rough measurement.

Figure 4 shows results on CBOOA corrected according to this assumption. In figure 5 , such a correction has not been made. In figures 3 and 4 the expansion coefficient has been calculated taking into account the temperature dependence of the mechanical threshold $\delta_{1 \mathrm{~h}}$ in the HOBHA and the CBOOA respectively [6,9].

The two different types of thermal thickness variation are not seen in every compound. While the rubbertype contraction of the layers is explained by the flexibility of the aliphatic chains, it is difficult to explain the solid-type dilation in the upper temperature region. We might think it is due to a variation of the positional order of the molecules. These molecules could glide with respect to each other, along the common alignment direction. Such an effect would lead close to the nematic phase to an increase of the layer thickness, and the inversion point for the expansion coefficient variation would correspond to the temperature for which the gliding of the molecules overcomes the contraction effect of the aliphatic chains.

Another surprising point is that, although these compounds present phase transitions of different nature, we do not see any significant pretransitional effect on the thresholds. In effect the threshold curves are similar for CBOOA which has a quasi-second order smectic-A to nematic transition and for BBAA which slows only a first order transition. On the other side of the smectic- $A$ temperature range the increase in threshold for HOBHA which has a second order smectic-A to smectic-C transition is similar to that of BBAA which has not such a transition. However, the poor temperature definition of our set-up may prevent us from observing any less obvious pretransition effect.

Finally, we do not see any clear evidence here of an effect which would be due to the bi-layered structure of the CBOOA.
5. Comparison with $X$-Ray diffraction measurements. - Such X-Ray diffraction measurements of thickness variation as a function of the temperature in the smectic phase have already been reported elsewhere [7]. They did not show any inversion of the expansion coefficient, in the studied compounds.

We have performed such an experiment on a thick ( $2 \mathrm{~mm}$ ) sample of CBOOA using a photon-localization counter associated with a SEIN multichannel. The temperature inhomegeneity on the whole sample is of about $0.5^{\circ} \mathrm{C}$ and the resolution of about $0.1^{\circ} \mathrm{C}$.

The results on thickness variation show (Fig. 6) a

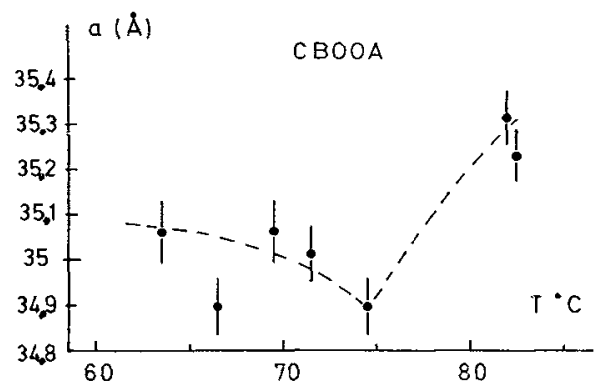

FIG. 6. - Variation of the layer thickness measured by X-Ray diffraction in CBOOA. The minimum corresponds to inversion of the expansion coefficient $\alpha$.

minimum as the temperature is varied which corresponds roughly to the inversion point of the expansion coefficient found previously (Fig. 5).

6. Conclusion. - We have shown that a rapid thermal gradient is equivalent to applying a destabilizing field (dilative stress) normally to the layers. The same effect can be seen, and the sign of the thermal variation easily verified, when transition between phases is made rapidly. For example when cooling down from the nematic to the smectic-A phase samples of CBOOA and BBAA undulations, then doublecrossed undulations, and finally a quasi regular texture of focal-conics domains appear. Such a highly deformed structure appears as the final stage of the undulations of layers when an elastic limit is overpassed. This shows that large thermal gradient might produce, without involving any phase change, strong distortions of structure which would be more or less reversible and which could lead to possible storage modes.

This thermo-mechanical effect would constitute a more sensitive way to study temperature dependence of length of long molecules in smectic phases than XRay diffraction. It might be possible that such thermal variations of layers thickness would have an influence in phase transition problems.

Practical applications of this effect could be imagined for the measurement of rapid small and local temperature variations.

We wish to thank G. Durand and P. G. de Gennes for very helpful discussions, A. Moudden and A. M. Levelut for help and assistance during the XRay scattering experiment. 


\section{References}

[1] Delaye, M., Ribotta, R. and Durand, G., Phys. Lett. 44A (1973) 139

[2] Clark, N. A., Meyer, R. B., Appl. Phys. Lett. 22 (1973) 10.

[3] De Gennes, P. G., Solid State Commun. 10 (1972) 753.

[4] RiвotтA, R., in Les Houches, Lectures notes in Theoretical Physics, Balian Ed. (Gordon \& Breach) 1973, p. 355.

[5] Ribotta, R., Salin, D. and Durand, G., Phys. Rev. Lett. 32 (1973) 6.
[6] Ribotta, R., Thesis $n^{\circ}$ 1450, Orsay (March 1975). A preliminary account of the effect described here is given in this reference, and has been presented at the "Conference de la SFP, Dijon June 1975 ».

[7] McMillan, W. L., Phys. Rev. A 6 (1972) 936.

[8] Ribotta, R., Meyer, R. B. and DuRand, G., J. Physique Lett. 35 (1974) L-161.

[9] Ribotta, R., C. R. Hebd. Séan. Acad. Sci. 279B (1974) 295. 